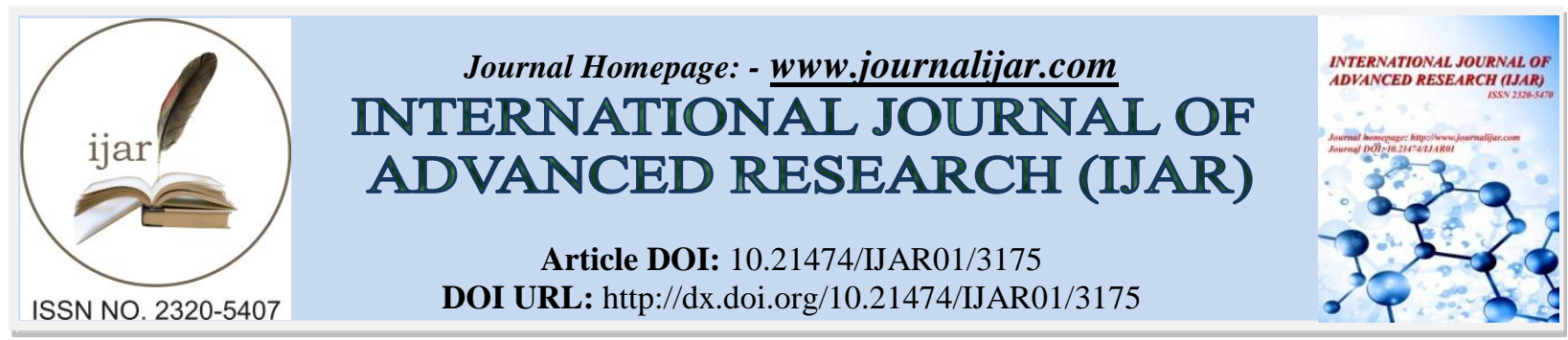

RESEARCH ARTICLE

\title{
CYTOGENETICS AND MOLECULAR GENETICS ON FEMALE INFERTILITY WITH SPECIAL EMPHASIS ON POLYCYSTIC OVARIAN SYNDROME
}

Josey Ann Jijo ${ }^{1}$, Arun William ${ }^{2}$, Aneesh $\mathbf{P}^{2}$, Leenamma Joseph ${ }^{1}$, Lija L Raju ${ }^{1}$, Viji Krishnan ${ }^{3}$ and Dinesh Roy $\mathbf{D}^{4}$.

1. Department of Zoology, Mar Ivanios College, Thiruvananthapuram, Kerala.

2. Research Scholar, Meenakshi University, West K K Nagar, Chennai, Tamil Nadu.

3. Department of Biochemistry, Jubilee Mission Medical College and Research Institute, Thrissur, Kerala.

4. Genetika, Centre for Advanced Genetic Studies, Pettah PO, Thiruvananthapuram, Kerala.

\section{Manuscript Info}

Manuscript History

Received: 18 December 2016

Final Accepted: 08 January 2017

Published: February 2017

Key words:-

Female infertility, Polycystic Ovarian Syndrome, Cytokinesis-block micronuclei (CBMN) assay

\begin{abstract}
Female infertility is defined as the inability to conceive naturally or to carry a pregnancy to full term. It occurs for almost $15 \%$ of all women worldwide. The etiology of infertility is an important criterion for recognition and characterization of infertile women. The common factors for infertility in females are anovulatory disorder, tubal factors, endometriosis, uterine and cervical factors. Infertility affects $40 \%$ of women with PCOS and is the most common cause of female infertility. The present study was undertaken to evaluate the cytogenetics and molecular genetics on female infertility with special emphasis on polycystic ovarian syndrome by investigating the various anthropometric and clinical aspects of the subjects. Seventy five female subjects with infertility and 50 healthy women without any chronic illness were involved in this study. Reproductive hormones namely leutinizing hormone ( $\mathrm{LH})$, follicle stimulating hormone (FSH), prolactin and estradiol were estimated in each subjects after obtaining their informed consent. Cytokinesis-block micronuclei (CBMN) assay was also carried out in the lymphocytes of the subjects to assess the somatic DNA damage. The study demonstrated that the micronuclei frequency significantly elevated in the study subjects than control subjects. Infertile women with various risk factors such as increasing age, BMI, family history of infertility, family history of cancer, menarche, endometriosis etc. can lead to increased genetic instabilities and the severity of infertility. Lifestyle modification with diet and exercise will reduce the risk for infertility.
\end{abstract}

Copy Right, IJAR, 2017,. All rights reserved.

\section{Introduction:-}

Female infertility is defined as the inability to conceive naturally or to carry a pregnancy to full term (Gaware et al., 2009). The incidence of female infertility is rising and varies from 10 to 20\% (Moghadam et al., 2013). Female infertility is caused by genetic, hormonal, or environmental factors. In addition, pelvic inflammatory disease, uterine fibroids, age-related factors, tubal blockage, and hostile cervical mucus can cause infertility in females (Olooto, 2012). Female infertility occurs in about $37 \%$ of all infertile couples (Unuane et al., 2011). 
The etiology is an important criterion for recognition and characterization for infertile subjects. Advanced age, high body mass index, age of onset of sexual activity, prior pelvic surgeries and stress were the most significant risk factors associated with women's infertility (Romero et al., 2008). Problems regarding menstruation (ammenhorroea, menorrhagia polymenhorroea, dysmenhorroea) along with insanitation are the major danger alarms (Maeda and Tsukamura, 2006). Any cause leading to irreversible or non-compensable damage to the genital tract, uterus, fallopian tubes or ovaries may cause inability to conceive (Jain et al., 2004; World Health Organization, 2003).

The polycystic ovary syndrome (PCOS) affects 7 to $8 \%$ of women (Azziz et al., 2004) and may be the most common cause of female infertility (Norman et al., 2002). Women with PCOS have an increased risk of miscarriage, gestational diabetes, preeclampsia and preterm labour (Boomsma et al., 2006).

Accumulating evidence suggests that genetic factors contribute to the etiology of female infertility in humans (The ESHRE Capri Workshop Group, 2008; Matzuk and Lamb, 2008). Genes involved in meiosis are also good candidates for genes contributing to female infertility (Sanderson et al., 2008). Karyotype analysis is also performed in women presenting with primary amenorrhoea, premature menopause, and recurrent pregnancy loss (ESHRE Capri workshop group, 2000). The sex chromosome aberrations and the presence of constitutional inversions, translocations, or small supernumerary marker chromosomes (sSMC) can lead both to infertility and repeated abortions (Liehr et al., 2004; Shah et al., 2003). Diminished ovarian reserve (DOR) is a primary infertility disorder characterized by a reduction in the number and/or quality of oocytes, usually accompanied by high folliclestimulating hormone (FSH) levels and regular menses (Broekmans et al., 2007). Cytogenetic studies of female patients enrolled in an intracytoplasmic sperm injection (ICSI) programme reviewed by Gekas et al., (2001) have shown an unexpectedly increased incidence of abnormal karyotypes, ranging from 1.1 to $9.8 \%$ when cases with low level sex chromosome mosaicism were included.

As many as $20 \%$ of women with infertility problems (including fecundability and early pregnancy loss) have been diagnosed with PCOS (Diamanti et al 1998). PCOS is the most common cause of menstrual irregularity that leads to infertility. There is now a greater focus on the management of the metabolic consequences of PCOS, primarly through lifestyle interventions to achieve weight loss and increase physical activity (Sevendsen et al., 2005). The investigation and management of female infertility can be done by changing lifestyle, regular exercise, dieting etc. and this is one of the debated topics. No serious attempts were made earlier to correlate DNA damage and female infertility with polycystic ovarian syndrome. Hence the present study was undertaken to correlate various cytogenetics and molecular genetics on female infertility with polycystic ovarian syndrome.

\section{Materials and Methods:-}

Seventy five study subjects with a clinical diagnosis of infertility referred from various infertility centers of Kerala to Genetika, Centre for Advanced Genetic studies, Trivandrum. Fifty healthy subjects without any chronic illness were also selected as control for this study. Detailed demographic, clinical and biochemical characteristics of the subjects were recorded using proforma. In this study, Cytokinesis Block Micronuclei (CBMN) assay was carried out in each subject. CBMN assay was performed by using Cytochalasin B for quantitating the extent of somatic DNA damages.

Seven $\mathrm{ml}$ of blood sample was collected by venepuncture. Two $\mathrm{ml}$ of blood was transferred into sodium heparinized vacuutainers for quantifying the extent of somatic DNA damages by Cytokinesis-Block Micronuclei (CBMN) assay. The remaining five $\mathrm{ml}$ of blood was transferred into a plain tube. Blood was allowed to clot, serum separated immediately. Blood sugar and lipid profile were estimated using semi-automated clinical chemistry analyzer.

Two $\mathrm{ml}$ blood was added to a culture tube containing $10 \mathrm{~mL}$ RPMI 1640 supplemented with $100 \mathrm{units} / \mathrm{mL}$ penicillin, $100 \mu \mathrm{g} / \mathrm{mL}$ streptomycin, $15 \%$ fetal bovine serum and $100 \mu \mathrm{g} / \mathrm{mL}$ phytohemagglutinin. Cytochalasin B was added to the cultures at a final concentration of $4.5 \mu \mathrm{g} / \mathrm{mL}$ (Sigma) after $44^{\mathrm{th}}$ hours of initiation of cells with phytohaemagglutinin. Cells were harvested after $72 \mathrm{hr}$ incubation, and they were treated with a hypotonic solution $(0.075 \mathrm{M} \mathrm{KCl})$ for $1 \mathrm{~min}$ and fixed in fresh fixative solution (methanol: acetic acid, 3:1). The cells were dropped onto slides and the slides were air dried and stained with 10\% Giemsa. Micronucleated cells were analyzed under light microscopy at 100X magnification. The number of micronuclei is not less than 1000 binucleated cells were scored and the distribution of micronuclei among binucleated cells was recorded. 


\section{Results:-}

In the present study 75 individuals were taken as the study subjects and 50 healthy individuals were taken as the control subjects. The study subjects showed a mean CBMN frequency of 13.18 while the control subjects showed a mean CBMN frequency of 10.63. This difference in mean CBMN frequencies showed a statistically significant difference.

Table 1:- Distribution of mean CBMN frequency according to various demographic characteristics

\begin{tabular}{|c|c|c|c|c|}
\hline Category & Variables & Total & Percentage $(\%)$ & Mean CBMN Frequency \\
\hline \multirow[t]{2}{*}{ Age (Years) } & $20-28$ & 40 & 53.3 & 13.01 \\
\hline & $29-36$ & 35 & 46.6 & 13.38 \\
\hline \multirow[t]{3}{*}{ Birth Order } & $<3$ & 51 & 68 & 13.02 \\
\hline & 4 to 6 & 20 & 26 & 13.46 \\
\hline & 7 to 9 & 4 & 5.3 & 13.76 \\
\hline \multirow[t]{3}{*}{ Residence } & Coastal & 8 & 10.6 & 12.98 \\
\hline & Rural & 52 & 69.3 & 13.11 \\
\hline & Urban & 15 & 20 & 13.54 \\
\hline \multirow{2}{*}{ Parental consanguinity } & Yes & 8 & 10.6 & 13.45 \\
\hline & No & 67 & 89.3 & 13.15 \\
\hline \multirow[t]{2}{*}{ Duration of married life (Years) } & 1 to 5 & 52 & 70 & 13.14 \\
\hline & 6 to 11 & 23 & 29.3 & 13.27 \\
\hline \multirow[t]{3}{*}{ Social Status } & High & 9 & 12 & 13.69 \\
\hline & Low & 2 & 2.6 & 13.11 \\
\hline & Medium & 64 & 85.3 & 13.11 \\
\hline \multirow[t]{3}{*}{ BMI $\left(\mathrm{Kg} / \mathrm{m}^{2}\right)$} & $<20$ & 1 & 1.33 & 12.06 \\
\hline & 20 to 25 & 42 & 56 & 13.02 \\
\hline & $>25$ & 32 & 42.66 & 13.33 \\
\hline
\end{tabular}

The subjects were grouped on their demographic characteristics such as age, birth order, residence, parental consanguinity, duration of married life, social status and BMI (Table 1). Among the 75 study subjects, 40 subjects (53.3\%) were between the age of 20 to 28 years and showed a mean CBMN frequency of 13.01. The highest mean CBMN frequency of 13.38 was shown by 35 subjects $(46.6 \%)$ of age between 29 to 36 years. The highest mean CBMN frequency (13.76) shown by subjects between 7 to 9 birth order. Majority of the study subjects were belonged to rural (69.3\%) followed by urban area (20\%) and coastal area (10.6\%). The highest mean CBMN frequency was observed in urban area (13.54). Subjects with parental consanguinity showed highest mean CBMN frequency of 13.45. Subjects having 6 to 11 years of married life showed highest mean CBMN frequency of 13.27. From the study subjects, $9(12 \%)$ subjects were showed a high social status with a highest mean CBMN frequency of 13.69. 64 subjects (85.3\%) were belonged to middle social status and showed a mean CBMN frequency (13.11). On the basis of BMI, subjects with $<20 \mathrm{Kg} / \mathrm{m}^{2}$ showed mean CBMN frequency of 12.06 and 20 to $25 \mathrm{Kg} / \mathrm{m}^{2}$ showed mean CBMN frequency of 13.02. Highest mean CBMN frequency (13.33) showed by subjects with BMI >25 $\mathrm{Kg} / \mathrm{m}^{2}$.

Table 2:- Distribution of mean CBMN frequency according to various clinical characteristics

\begin{tabular}{|l|l|l|l|l|}
\hline Category & Variables & Total & $\begin{array}{l}\text { Percentage } \\
\%)\end{array}$ & Mean CBMN Frequency \\
\hline \multirow{2}{*}{ Family H/o infertility or subfertility } & Yes & 6 & 8 & 13.19 \\
\cline { 2 - 5 } & No & 69 & 92 & 13.18 \\
\hline \multirow{2}{*}{ Family H/o cancer } & Yes & 3 & 4 & 13.22 \\
\cline { 2 - 5 } & No & 72 & 96 & 13.18 \\
\hline \multirow{2}{*}{ Family H/o chronic illness } & Yes & 71 & 94.6 & 13.19 \\
\cline { 2 - 5 } & No & 4 & 5.3 & 12.93 \\
\hline \multirow{2}{*}{ H/o X-ray exposure } & Yes & 70 & 93.3 & 13.19 \\
\cline { 2 - 5 } & No & 5 & 6.6 & 13.05 \\
\hline \multirow{2}{*}{ Menstrual periods } & Irregular & 38 & 50.6 & 13.21 \\
\cline { 2 - 5 } & Regular & 37 & 49.3 & 13.16 \\
\hline
\end{tabular}




\begin{tabular}{|l|l|l|l|l|}
\hline \multirow{2}{*}{ Menarche (years) } & 13 to 15 & 69 & 92 & 12.87 \\
\cline { 2 - 5 } & 16 to 18 & 6 & 8 & 13.21 \\
\hline \multirow{3}{*}{ Endometriosis } & Yes & 9 & 12 & 13.22 \\
\cline { 2 - 5 } & No & 66 & 88 & 12.91 \\
\hline \multirow{2}{*}{ Contraceptive drugs used } & Yes & 12 & 16 & 13.18 \\
\cline { 2 - 5 } & No & 63 & 84 & 13.16 \\
\hline \multirow{2}{*}{ Clinical conditions } & Abortion & 30 & 40 & 13.35 \\
\cline { 2 - 5 } & Infertility & 45 & 60 & 13.07 \\
\hline
\end{tabular}

The subjects were grouped on their clinical characteristics such as family history of infertility or subfertility, family history of cancer, family history of chronic illness, history of X-ray exposure, menstrual periods, menarche, endometriosis, contraceptive drugs used and clinical condition (Table 2). Subjects with family history of infertility/subfertility (8\%) showed highest mean CBMN frequency of 13.19. Subjects with family history of cancer showed higher mean CBMN frequency (13.22) than subjects without family history of cancer. Family history of chronic illness was reported in 71 out of 75 study subjects with mean CBMN frequency of 13.19. Subjects with irregular menstrual periods showed high mean CBMN frequency of 13.21 . Majority of study subjects $(\mathrm{n}=69 ; 92 \%)$ attained menarche between 13 to 15 years of age and the remaining 6 subjects attained menarche between 16 to 18 years. Those who attained menarche between 16 to 18 years of age showed highest mean CBMN frequency of 13.21. Nine subjects had endometriosis with mean CBMN frequency of 13.22. Consumption of contraceptive drugs was reported in 12 out of 75 study subjects and their mean CBMN frequency was 13.18 .

Table 3:- Distribution of mean CBMN frequency according to various biochemical and endocrinological characteristics

\begin{tabular}{|c|c|c|c|c|}
\hline Category & Variables & Total & Percentage (\%) & $\begin{array}{l}\text { Mean CBMN } \\
\text { Frequency }\end{array}$ \\
\hline \multirow{3}{*}{$\begin{array}{l}\text { Fasting blood sugar (FBS) } \\
(\mathrm{mg} / \mathrm{dl})\end{array}$} & 70 to 100 & 7 & 9.33 & 13.17 \\
\hline & 101 to 126 & 30 & 40 & 13.19 \\
\hline & $>126$ & 38 & 50.6 & 13.20 \\
\hline \multirow[t]{2}{*}{ Total Cholesterol (mg/dl) } & $<200$ & 26 & 34.6 & 13.04 \\
\hline & $>200$ & 49 & 65.2 & 13.2 \\
\hline \multirow[t]{3}{*}{$\operatorname{HDL}(\mathrm{mg} / \mathrm{dl})$} & 21 to 31 & 18 & 24 & 13.27 \\
\hline & 32 to 42 & 44 & 58.6 & 13.22 \\
\hline & 43 to 51 & 12 & 16 & 12.95 \\
\hline \multirow[t]{3}{*}{$\mathrm{LDL}(\mathrm{mg} / \mathrm{dl})$} & $<100$ & 6 & 8 & 13.13 \\
\hline & 100 to 150 & 32 & 42.6 & 13.18 \\
\hline & $>150$ & 37 & 49.3 & 13.19 \\
\hline \multirow[t]{3}{*}{$\mathrm{TG}(\mathrm{mg} / \mathrm{dl})$} & $<150$ & 53 & 70.6 & 13.04 \\
\hline & 150 to 250 & 19 & 25.3 & 13.10 \\
\hline & $>250$ & 3 & 4 & 13.22 \\
\hline \multirow{3}{*}{$\begin{array}{l}\text { Follicle stimulating (FSH) } \\
(\mathrm{mIU} / \mathrm{ml})\end{array}$} & $<25$ & 41 & 54.6 & 13.09 \\
\hline & 25 to 30 & 12 & 16 & 13.24 \\
\hline & $>30$ & 22 & 29.3 & 13.37 \\
\hline \multirow{3}{*}{$\begin{array}{l}\text { Luteinizing hormone (LH) } \\
(\mathrm{mIU} / \mathrm{ml})\end{array}$} & $<45$ & 16 & 21.33 & 13.04 \\
\hline & 45 to 60 & 41 & 53.33 & 13.18 \\
\hline & $>60$ & 19 & 25.33 & 13.30 \\
\hline \multirow{3}{*}{ Estradiol (pg/ml) } & $<25$ & 8 & 10.6 & 12.84 \\
\hline & 25 to 75 & 36 & 48 & 13.20 \\
\hline & $>75$ & 31 & 41.3 & 13.24 \\
\hline \multirow[t]{2}{*}{ Prolactin (ng/l) } & $<25$ & 24 & 32 & 13.02 \\
\hline & $\geq 25$ & 51 & 68 & 13.53 \\
\hline
\end{tabular}

The subjects were grouped on their various biochemical and endocrinological characteristics such as FBS, total cholesterol, HDL, LDL, TG, FSH, LH, Estradiol and Prolactin (Table 3). Normal FBS was reported in 7 (9.33\%) 
subjects and remaining subjects were pre-diabetic and diabetic. The mean CBMN frequency of pre-diabetic subjects and diabetic subjects were 13.19 and 13.20. Normal serum total cholesterol was reported only in 26 (34.6\%) study subjects and the remaining subjects were hypercholestrolimic $(>200 \mathrm{mg} / \mathrm{dl})$. The mean CBMN frequency of hypercholestrolimic subjects were 13.2. Subjects with triglyceride value $<150 \mathrm{mg} / \mathrm{dl}$ showed mean CBMN frequency of 13.04. Highest mean CBMN frequency (13.22) was shown by subjects with triglyceride value $>250$ $\mathrm{mg} / \mathrm{dl}$. The study subjects showed FSH value $>30 \mathrm{mIU} / \mathrm{ml}$ had higher mean CBMN frequency (13.37) compared to $<25 \mathrm{mIU} / \mathrm{ml}$ (13.09) and 25 to $30 \mathrm{mIU} / \mathrm{ml}$ (13.24). Study subject with LH level $>60 \mathrm{mIU} / \mathrm{ml}$ showed highest mean CBMN frequency of 13.30. Subjects with $>75 \mathrm{pg} / \mathrm{ml}$ value of estradiol showed highest mean CBMN frequency of 13.24. Majority of the subjects have prolactin level $\geq 25 \mathrm{ng} / \mathrm{l}$ and showed highest mean CBMN frequency of 13.53.

\section{Discussion:-}

The prevalence of female infertility is varies worldwide ranging from $3 \%$ to $7 \%$. Polycystic ovarian syndrome is a common condition estimated to affect $4-18 \%$ women in the reproductive age. PCOS is associated with reproductive, psychological, metabolic and cardiovascular diseases (Boomsma et al., 2006).

According to Zlotogora, (2006) in communities with a high level of consanguineous marriage, diagnosis of a recessive disorder in one or more members of the same family is generally indicative of a recent mutation, whereas the presence of a rare disorder in several families suggests an older mutational event or previous admixture through marriage with a person from another community. In the present study, subjects with parental consanguinity showed highest mean CBMN frequency.

Mokhtar et al., (2006) revealed that females with the age of menarche more than 15 years were more risky to develop infertility than those with age of menarche less than 15 years. In the present study, the subjects with advancing age of menarche were showed a high mean CBMN frequency.

BMI is a common feature in women with PCOS, with prevalence of 30-70\%. Certain single nucleotide polymorphism associated with obesity and it contributed to elevate the body mass index in PCOS (Ewens et al., 2011). The present study showed a high CBMN frequency among the subjects with obesity.

According to Wijeyaratne et al., (2005) those with PCOS had significantly higher median BMI. Regarding BMI, $69.2 \%$ of overweight/obese patients had polycystic ovary morphology. The higher incidence of overweight may be linked to the lack of exercise amongst women and fatty food habits. Increasing BMI was significantly related to an increasing trend in the proportion of women with the metabolic syndrome. PCOS is one of the most common risk factor among female infertility. Thus in the present study it is showed that mean CBMN frequency increases with increasing the BMI.

According to Guastella et al., (2010) patients with polycystic ovaries have statistically significant higher LH levels and LH/FSH ratios than patients with normal ovaries. In the present study, majority of the subjects were shown hormonal disturbances and also increased mean CBMN frequency.

\section{Conclusion:-}

The present study involves Cytogenetics and Molecular Genetics on Female Infertility with Special Emphasis on Polycystic Ovarian Syndrome. The distribution of mean CBMN frequency according to demographic, clinical and biochemical characteristics of the study subjects was observed. Age, birth order, parental consanguinity, and BMI etc. showed increased level of mean CBMN frequency. The level of mean CBMN frequency was high among those who have the family history of infertility, family history of cancer and family history of chronic illness. FBS, total cholesterol, FSH, LH, prolactin and estradiol were also found to be significantly elevated in study subjects. These findings suggest that the women with PCOS have a high risk for infertility. While PCOS cannot be prevented or cured, it can be controlled, with varying degrees of success, by maintaining a healthy diet and by exercising. Healthy lifestyle factors, including exercise, are associated significantly with reduced DNA damage. 


\section{Reference:-}

1. Azziz, R,. Woods, K.S., Reyna, R., Key, T.J., Knochenhauer, E.S., Yildiz, B.O. (2004): The prevalence and features of the polycystic ovary syndrome in an unselected population. J ClinEndocrinol Metab., 89: 27452749.

2. Boomsma, C.M., Eijkemans, M.J., Hughes, E.G., Visser, G,H., Fauser, B.C., Macklon, N.S. (2006): A metaanalysis of pregnancy outcomes in women with polycystic ovary syndrome. Hum Reprod Update., 12: 673-83.

3. Gaware, V.M., Parjane, S.K., Merekar, Abhijit, N., et al., (2009): Female infertility and its treatment by alternative medicine: a review. J Chem Pharm Res., 1: 148-162.

4. Gekas, J., Thepot, F., Turleau, C., et al., (2001): Chromosomal factors on infertility in candidate couples for ICSI: an equal risk of constitutional aberrations in women and men. Hum Reprod., 16: 82-90.

5. Matzuk, M.M., Lamb, D.J. (2008): The biology of infertility: research advances and clinical challenges. Nat Med., 14: 1197 - 1213.

6. Norman, R.J., Davies, M.J., Lord, J. and Moran, L.J. (2002): Role of lifestyle modification in polycystic ovary syndrome. Trends Endocrinol Metab., 13: 251-257.

7. Olooto. W.E., Amballi, A.A., Banjo, T.A. (2012): A review of female infertility important etiological factors and management. J Microbiol Biotech Res., 2(3): 379-385.

8. Sanderson, M.L., Hassold, T.J., Carrell, D.T., (2008): Proteins involved in meiotic recombination: a role in male infertility? SystBiolReprod Med., 54: 57- 74.

9. The ESHRE Capri Workshop Group. (2008): Genetic aspects of female reproduction. Hum Reprod Update., 14: $293-307$.

10. Unuane, D., Tournaye, H., Velkeniers, B., Poppe, K. (2011): Endocrine disorders \& female infertility. Best Pract Res ClinEndocrinolMetab., 25(6): 861-873.

11. Guastella, E., Longo, R.A., Carmina, E. (2010): Clinical and endocrine characteristics of the main polycystic ovary syndrome phenotypes. Fertil Steril., 94(6): 2197-2201.

12. Wijeyaratne, C.N., Jayasinghe, A., de Silva, D.G., Parkes, A.B., Lazarus, J.H., Premawardhana, L.D. (2005): Iodine prophylaxis, goitre and thyroid autoimmunity in Sri Lanka Ceylon Med J. Mar., 50(1): 20-3.

13. Ewens, K.G., Jones, M.R., Ankener, et al., (2011): FTO and MC4R gene variants are associated with obesity in polycystic ovary syndrome, PLoS One.,6: Article ID e16390.

14. Mokhtar, S., Hassan, H.A., Mahdy, N., Elkhwsky, F., Shehata, G. (2006): Risk factors for primary andsecondary female infertility in Alexandria: ahospital-based case-control study. JMRI., 27: $255-261$.

15. Zlotogora, J., Hujera,t Y,, Barges, S., Shalev, S.A., Chakravarti, A. (2006): The fate of 12 recessive mutations in a single village. Ann Hum Genet., 202-208.

16. Moghadam, D.A., Delpisheh, A. and Khosravi, A. (2013): Epidemiology of Female Infertility; A Review of Literature. Biosciences Biotechnology Research Asia., 559-567.

17. Maeda, K., Tsukamura, H. (2006): The Impact of Stress on Reproduction: are Glucocorticoids Inhibitory or Protective to Gonadotropin Secreation? Endocrinology., 147: 1085-6.

18. Jain, V., Saha, S.C., Bagga, R, Gopalan S. Unsafe abortion: a neglected tragedy. J Obstet Gynaecol Res. 2004; 30: 197-201.

19. World Health Organization. (2003): Safe Abortion: Technical Policy Guidance for Health System., 13-4.

20. ESHRE Capri workshop group (2000): Optimal use of infertility diagnostic tests and treatments. Hum Reprod. $15,723-732$.

21. Broekmans, F.J., Knauff, E.A., te Velde, E.R., Macklon, N.S., Fauser, B.C. (2007). Female reproductive ageing: current knowledge and future trends. Trends Endocrinol Metab., 18: 58 - 65.

22. Liehr, T., Claussen, U., Starke, H. (2004). Small supernumerary marker chromosomes (sSMC) in humans. Cytogenet Genome Res., 107: 55-67.

23. Shah, K., Sivapalan, G., Gibbons, N., Tempest, H,, Griffin, D.K. (2003). The genetic basis of infertility. Reproduction; 126:13-25.

24. Diamanti-Kandarakis. E., Kouli, C., Tsianateli, T., Bergiele, A. (1998). Therapeutic effects of metformin on insulin resistance and hyperandrogenism in polycystic ovary syndrome. Eur J Endocrinol., 138: 269-274.

25. Svendsen, P.F., Nilas, L., Norgaard, K., Madsbad, S. (2005). Polycystic ovary syndrome. New pathophysiological discoveries therapeutic consequences. Ugeskr Laeger., 22;167(34): 3147-51. 